\title{
Oligomeric proanthocyanidin fractions from fresh tea leaves and their antibacterial activity against Staphylococcus aureus
}

\author{
N. Savitri Kumar ${ }^{1 *}$, B.M. Ratnayake Bandara ${ }^{2,3}$, Sujeewa K. Hettihewa ${ }^{2,3}$ and Gehan J. Panagoda ${ }^{4}$ \\ ${ }^{I}$ Institute of Fundamental Studies, Hantana Road, Kandy. \\ ${ }^{2}$ Department of Chemistry, Faculty of Science, University of Peradeniya, Peradeniya. \\ ${ }^{3}$ Postgraduate Institute of Science, University of Peradeniya, Peradeniya. \\ ${ }^{4}$ Division of Microbiology, Faculty of Dental Sciences, University of Peradeniya, Peradeniya.
}

Revised: 5 February 2014; Accepted: 9 May 2014

\begin{abstract}
Purification of the proanthocyanidin (PA) extract of fresh tea [Camellia sinensis (L.) Kuntze] leaves by Sephadex LH-20 column chromatography followed by high-speed counter-current chromatography (HSCCC) using the two phase solvent system hexane-ethyl acetate-methanol-water (1:5:1:5) furnished three $\mathrm{PA}$ fractions $\mathrm{PA}_{1}-\mathrm{PA}_{3}$. The electro-spray ionization mass spectrometry (ESI-MS) of the PA fractions indicated the presence of oligomeric PAs in all three PA fractions. Antibacterial activity against Staphylococcus aureus and their minimum inhibitory concentration (MIC) values were determined using the agar well diffusion assay and the agar dilution method, respectively. The antibacterial activity was observed for the selected PA fractions with MIC values in the range $512-1024 \mu \mathrm{g} / \mathrm{mL}$ against methicillin-resistant $S$. aureus (MRSA, 12 strains), methicillin-susceptible $S$. aureus (MSSA, 1 strain) and two standard strains of $S$. aureus, NCTC 6571 and ATCC 25923S. This is the first report of antibacterial activity displayed by tetrameric A-type PAs in the extracts of fresh tea leaves.
\end{abstract}

Keywords: Antibacterial, Camellia sinensis, oligomeric proanthocyanidins, Staphylococcus aureus, tea.

\section{INTRODUCTION}

Tea made from the tender leaves of Camellia sinensis, var assamica is one of the most widely consumed beverages in the world. The health - giving properties of tea are well documented and have been attributed to the wide range of polyphenolic compounds, including flavan-3-ols (catechins), flavanol glycosides and proanthocyanidins (PAs) present in tea leaves.
Dimeric, oligomeric and polymeric PAs, also known as condensed tannins and leucocyanidins are an ubiquitous group of plant phenols, which has attracted a great deal of attention in the fields of nutrition, health and medicine because of their potent antioxidant properties. The term proanthocyanidin derives from the fact that these compounds yield anthocyanidins on heating with aqueous acids. PAs isolated from tea comprise about $2 \%$ of the dry weight of the leaf (Robertson, 1992).

The flavan-3-ols found commonly in PAs are $(+)$-afzelechin, $(+)$-catechin and $(+)$-gallocatechin and their diastereomers (-)-epiafzelechin, (-)-epicatechin and (-)-epigallocatechin (Figure 1). In B-type PAs the inter-flavanol links are $\mathrm{C}-\mathrm{C}$ bonds between the $\mathrm{C} 4$ of one flavanol unit (upper unit) and the $\mathrm{C} 8$ or $\mathrm{C} 6$ of another (lower unit), while in A-type PAs there are two linkages (C-O and $\mathrm{C}-\mathrm{C}$ ) between two of the flavanol units.

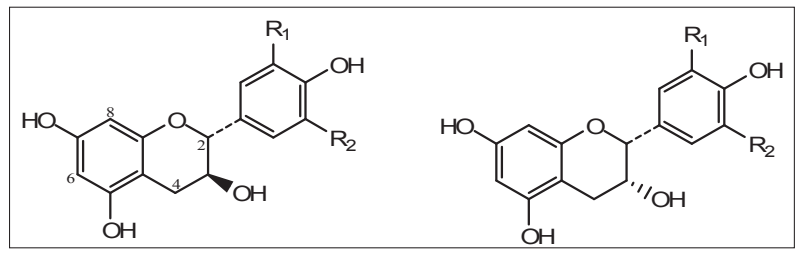

$\begin{array}{llllll}\text { Flavan-3-ol } & \mathrm{R}_{1} & \mathrm{R}_{2} & \text { Flavan-3-ol } & \mathrm{R}_{1} & \mathrm{R}_{2-} \\ \text { (+)-afzelechin } & \mathrm{H} & \mathrm{H} & \text { (-)-epiafzelechin } & \mathrm{H} & \mathrm{H} \\ \text { (+)-catechin } & \mathrm{H} & \mathrm{OH} & \text { (-)-epicatechin } & \mathrm{H} & \mathrm{OH} \\ \text { (+)-gallocatechin } & \mathrm{OH} & \mathrm{OH} & \text { (-)-epigallocatechin } & \mathrm{OH} & \mathrm{OH}\end{array}$

Figure 1: Chemical structures of flavan-3-ols in tea 
B-type PAs have been isolated from many different plant species while A-type PAs have been reported from a few natural sources including cranberry [Vaccinium macrocarpon (Aiton)] (Foo et al., 2000; Howell et al., 2005), cinnamon [Cinnamomum zeylanicum (Blume)] (Nonaka et al., 1983) and Pavetta owariensis (P Beauv.) (Balde et al., 1990). Their presence in these plants have been linked with their use in medicinal preparations. The physiological properties of PAs that are beneficial to health depend on the degree of polymerization as well as the nature of the inter-flavan linkage.

The extraction of tea leaves by aqueous $70-80 \%$ acetone (Hashimoto et al., 1989, Lakenbrink et al., 1999) and repeated chromatography have been used for the separation of B-type PAs (Nonaka et al., 1984; Kiehne et al., 1997; Lakenbrink et al., 1999). A dimeric A-type PA, prodelphinidin A-2,3'-O-galllate (1), along with the other PAs have been isolated from an aqueous $80 \%$ acetone extract of Oolong tea after repeated chromatography (Hashimoto et al., 1989). This is the only previous report of the occurrence of A-type PAs in tea.

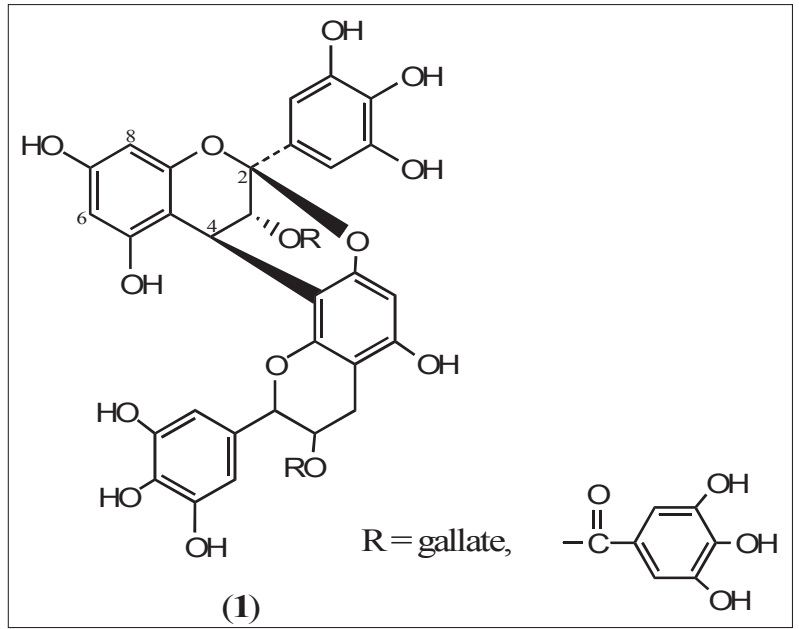

Figure 2: Structure of prodelphinidin A 2,3'-O-gallate

Many classes of polyphenolics including PAs from tea, have been separated using high-speed counter-current chromatography (HSCCC), a support-free liquid-liquid chromatographic method (Degenhardt et al., 2000; Yanagida et al., 2006; Kumar et al., 2009).

This paper describes the separation of oligomeric proanthocyanidin fractions from an aqueous acetone extract of tea leaves using Sephadex LH-20 chromatography and HSCCC, and the evaluation of their antibacterial activity against methicillin-resistant
Staphylococcus aureus (MRSA) and methicillinsusceptible $S$. aureus (MSSA). The low resolution electrospray ionization-mass spectrometry (LR-ESIMS) of the PA fractions suggested that these fractions were mixtures of tetrameric PAs (with both A-type and B-type linkages) as well as dimeric PAs. To the best of our knowledge, tetrameric A-type PAs from tea have not been separated before and has been reported by us for the first time (Kumar et al., 2013).

\section{METHODS AND MATERIALS}

Tender tea shoots were collected from the cultivar TRI 2025 (Tea Research Institute, Talawakelle) and chromatographic fractions were analyzed using commercial TLC plates (Merck Silica Gel $60 \mathrm{~F}_{254}$ ) and developed with the solvent system ethyl acetate-waterformic acid (90:05:05). A $1 \%(\mathrm{w} / \mathrm{v})$ solution of $p-N, N-$ dimethyl aminocinnamldehyde (DMACA) spray reagent in methanolic sulphuric acid $\left(8 \mathrm{~mL} \mathrm{H}_{2} \mathrm{SO}_{4}\right.$ and $100 \mathrm{~mL}$ methanol) was used to visualize the spots (Li et al., 1996; Rohr et al., 2000). The PA containing fractions were located by TLC as purplish blue spots with DMACA reagent.

\section{Extraction of PAs}

Cold aqueous $70 \%$ acetone $(200 \mathrm{~mL})$ containing sodium ascorbate $(0.2 \mathrm{~g})$ was used to extract the freeze-dried tea leaves $(100 \mathrm{~g})$, and filtered. The aqueous phase was saturated with sodium chloride $(30 \mathrm{~g})$ and the green upper phase was evaporated on a rotavapor under reduced pressure $\left(\leq 30{ }^{\circ} \mathrm{C}\right)$ to remove acetone, and filtered to remove the precipitated chlorophyll. Distilled water $(20 \mathrm{~mL})$ was added into the filtered extract and partitioned with dichloromethane $(20 \mathrm{~mL} \times 2)$ to remove chlorophyll and caffeine. The lower phase was discarded and the upper aqueous phase was partitioned with hexane $(100 \mathrm{~mL} \times 2)$, and the aqueous phase was concentrated and freeze-dried to yield the PA extract as a pale brown powder $(2.5 \mathrm{~g})$. The TLC indicated the presence of PAs and some monomeric flavan-3-ols (catechins) in the aqueous acetone extract from tea leaves.

\section{Sephadex LH-20 chromatography}

The PA extract (1.5 g in $9 \mathrm{~mL}$ of $50 \%$ aqueous methanol) was chromatographed on a Sephadex LH-20 column (Amersham Pharmacia Biotech, Uppsala, Sweden, $20 \times 2.3 \mathrm{~cm}$ ) pre-equilibrated with aqueous $50 \%$ methanol $(800 \mathrm{~mL})$, and then eluted with aqueous $50 \%$ methanol $(270 \mathrm{~mL})$ to remove the remaining catechins. The eluted fractions were monitored by TLC (Rohr et al., 2000): 
fractions $F_{1}(690 \mathrm{mg}), F_{2}(24 \mathrm{mg}), F_{3}(83 \mathrm{mg})$ and $F_{4}$ $(237 \mathrm{mg})$. PA containing fractions $\mathrm{F}_{3}(83 \mathrm{mg})$ and $\mathrm{F}_{4}(237$ $\mathrm{mg}$ ) were eluted using aqueous $70 \%$ acetone. The TLC revealed that fraction $\mathrm{F}_{1}(690 \mathrm{mg})$ contained monomeric flavan-3-ols while fraction $\mathrm{F}_{2}(24 \mathrm{mg})$ contained both monomeric flavan-3-ols and PAs. Fractions $\mathrm{F}_{3}(83 \mathrm{mg})$ and $\mathrm{F}_{4}(237 \mathrm{mg})$ contained only PAs. The major fraction $\mathrm{F}_{4}$ was subjected to fractionation by HSCCC.

\section{High-speed counter-current chromatography (HSCCC)}

Distilled and degassed (30 $\mathrm{min})$ solvents were used for HSCCC. The HSCCC Model CCC-1000-PharmaTech Research Corporation, Baltimore, MD, USA was used for the separation. The preparative coil (volume capacity of $300 \mathrm{~mL}$ ) had an internal diameter of $2.6 \mathrm{~mm}$, a $\beta$-value of 0.8 and a revolution radius of $7.5 \mathrm{~cm}$. The hexane-ethyl acetate-methanol-water system $\mathbf{A}$ (1:5:1:5) was selected for the separation on the basis of partition coefficient $\left(\mathrm{K}_{\mathrm{D}} 1.02\right)$, settling time (Ito \& Conway, 1996) and stationary phase retention (Shibusawa et al., 2000; Kumar et al., 2009). The aqueous phase was used as the mobile phase.

The $\mathrm{F}_{4}$ extract (200 $\mathrm{mg}$ in $5 \mathrm{~mL}$ of mobile phase) was injected into the HSCCC and fractions $(\sim 0.5 \mathrm{~mL})$ were collected (elution speed of $2.0 \mathrm{~mL} \mathrm{~min}^{-1}$ and rotational speed of $800 \mathrm{rpm})$. The effluent from the outlet of the column was monitored continuously with a UV detector and the PA fractions were collected manually.

\section{ESI-MS spectrometry}

Low resolution ESI-MS spectra were run by direct injection (detector temperature $225{ }^{\circ} \mathrm{C}$ ) on a thermo electron Finnigan LTQ LC-MS system (Thermoscientific, FL, USA) with ESI system (ionization spray voltage $4.31 \mathrm{~V}$, capillary voltage $2.97 \mathrm{~V}$ ) at the Harbour Branch Oceanographic Institute at Florida Atlantic University. The compounds were dissolved in MeOH-water (1:1) with a trace of formic acid for positive ion detection while a trace of $\mathrm{NH}_{4} \mathrm{OH}$ was added for negative mode detection.

\section{Bacterial isolates and growth conditions}

Standard strains of Staphylococcus aureus (NCTC 6571 and ATCC 25923) and a total of 12 MRSA and 11 MSSA strains obtained from fresh clinical isolates (collected from the Division of Microbiology, Faculty of Dental Sciences, University of Peradeniya and the
Microbiology Laboratory, Teaching Hospital, Peradeniya) were used in the study. These cultures were maintained at $-70{ }^{\circ} \mathrm{C}$ and the purity of the cultures was ascertained by using standard laboratory techniques. A loopful of the organism was taken from the bacterial colonies grown overnight on blood agar and suspended in sterile distilled water. The turbidity of the bacterial suspension was adjusted using $0.5 \mathrm{MacFarland}$ standard $\left(10^{8} \mathrm{CFU} / \mathrm{mL}\right)$.

\section{Antibacterial activity}

Susceptibility tests were performed by the MuellerHinton-Agar (MHA) well diffusion method (Valgas et al., 2007). The MHA plates (90 mm diameter, $20 \mathrm{~mL}$ ) were inoculated with the bacterial suspension $(2.0 \mathrm{~mL})$ by the pouring method. The extra volume was removed with a micropipette and the plates were kept inside an oven at $44{ }^{\circ} \mathrm{C}$ for $20 \mathrm{~min}$ until completely dry. Wells (diameter, $9 \mathrm{~mm}$ ) were punched in the agar and filled with the extracts $(200 \mu \mathrm{L})$. The plates were incubated at $37{ }^{\circ} \mathrm{C}$ for $24 \mathrm{~h}$. Antibacterial activity was evaluated by measuring the diameter of the inhibition zone along the two axes perpendicular to each other. Methicillin $(10 \mu \mathrm{g})$ for MSSA and gentamicin ( $5 \mu \mathrm{g})$ for MRSA were used as the positive controls, while sterile distilled water was used as the negative control. $\mathrm{F}_{4}$ (which contained only PAs) was found to be the most active in the agar well diffusion assay and was used for further studies.

\section{Determination of minimum inhibitory concentration (MIC)}

The MIC values of the three PAfractions, $\mathrm{PA}_{1}-\mathrm{PA}_{3}$ obtained from $\mathrm{F}_{4}$ were determined against two standard $S$. aureus strains (NCTC 6571 and ATCC 25923), 12 MRSA strains and 11 MSSA strains using an agar double dilution (BSAC) method (Andrews, 2001). Each of $\mathrm{PA}_{1}-\mathrm{PA}_{3}$ $(40 \mathrm{mg})$ was dissolved in sterile distilled water $(4.00 \mathrm{~mL})$ to give the stock solutions of $10 \mathrm{mg} / \mathrm{mL}$. A double dilution series was prepared from each stock solution by dispensing the under-mentioned amounts (2048, 1024, $512,256,128,64 \mu \mathrm{L}$ ) into labelled screw-capped bottles with a micropipette to give the final concentrations of PAs $(1024,512,256,128,64,32 \mu \mathrm{g} / \mathrm{mL})$. Sterilized cooled molten MHA $(20 \mathrm{~mL})$ at $50{ }^{\circ} \mathrm{C}$ was thoroughly mixed with the previously prepared dilution series in each screw-capped bottle. These were poured into sterile petri dishes (90 $\mathrm{mm}$ diameter) and allowed to set on a level surface. Suspenions of NCTC 6571, ATCC 25923, MRSA and MSSA that were adjusted to 0.5 MacFarland standard were spotted onto agar plates $(10 \mu \mathrm{L})$ using a micropipette. Agar plates were incubated aerobically at $37{ }^{\circ} \mathrm{C}$ for $24 \mathrm{~h}$. 


\section{RESULTS AND DISCUSSION}

\section{Separation of PAs using Sephadex LH-20 chromatography}

The catechins and PAs present in the lipid free aqueous $70 \%$ acetone extract of freeze dried tea leaves were separated by Sephadex LH-20 chromatography. Fractions $\mathrm{F}_{3}-\mathrm{F}_{4}$ were collected when the TLC indicated that PAs were being eluted.

\section{Separation of PA fractions by HSCCC}

Fraction $\mathrm{F}_{4}$ having shown considerable antibacterial activity (see below), was subjected to further fractionation using HSCCC. The two phase solvent system hexaneethyl acetate-methanol-water (1:5:1:5) used for the separation of catechins (Kumar et al., 2005) and PAs (Kumar et al., 2009) was selected for the separation of the PA extract. TLC (DMACA reagent) was used to monitor, collect and combine the PA containing fractions. Three HSCCC separations of $\mathrm{F}_{4}$ (200 $\mathrm{mg}$ each) yielded the four fractions $\mathrm{PA}_{1}(52 \mathrm{mg}), \mathrm{PA}_{2}$ (41 mg), $\mathrm{PA}_{3}(41 \mathrm{mg})$ and $\mathrm{PA}_{4}$ (26 mg).

The PA fractions separated using HSCCC were studied by TLC and their $\mathrm{R}_{\mathrm{f}}$ values were compared with those reported (Rohr et al., 2000) for oligomeric PAs, and with the $R_{f}$ value $(0.76)$ observed for an authentic sample of epigallocatechin gallate. The $\mathrm{R}_{\mathrm{f}}$ values observed on TLC suggested the presence of tetramers in $\mathrm{PA}_{1}\left(\mathrm{R}_{\mathrm{f}} 0.26\right)$, trimers in $\mathrm{PA}_{2}\left(\mathrm{R}_{\mathrm{f}} 0.35\right)$, dimers in $\mathrm{PA}_{3}\left(\mathrm{R}_{\mathrm{f}} 0.6\right)$, while $\mathrm{PA}_{4}$ contained a monomer $\left(\mathrm{R}_{\mathrm{f}} 0.76\right)$.

\section{ESI-MS mass spectrometry}

The stereoisomers of catechin and epicatechin cannot be distinguished during ESI-MS analysis and the notation (epi)catechin has been used in the discussion. Assignments were made based on the molecular mass of the peaks observed.

The presence of both A- and B-type PA tetramers composed of (epi)catechin, (epi)gallocatechin and (epi)afzelechin units, were indicated by the $\mathrm{M}^{+}$ions at $\mathrm{m} / \mathrm{z} 1168.6,1152.8,1141.7,1139.9,1138.7,1136.8$, 1134.8, 1132.7 and 1130.9 observed in the ESI-MS spectrum of PA. Possible structures for A- and B-type PA tetramers are shown in Figure 3.

Although the TLC comparison of $\mathrm{R}_{\mathrm{f}}$ values suggested that $\mathrm{PA}_{2}$ was probably a trimeric $\mathrm{PA}$ fraction, $\mathrm{M}^{+}$ions attributable to a trimeric PA were not observed in the ESI-MS (positive ionization mode) of $\mathrm{PA}_{2}$. Peaks due to

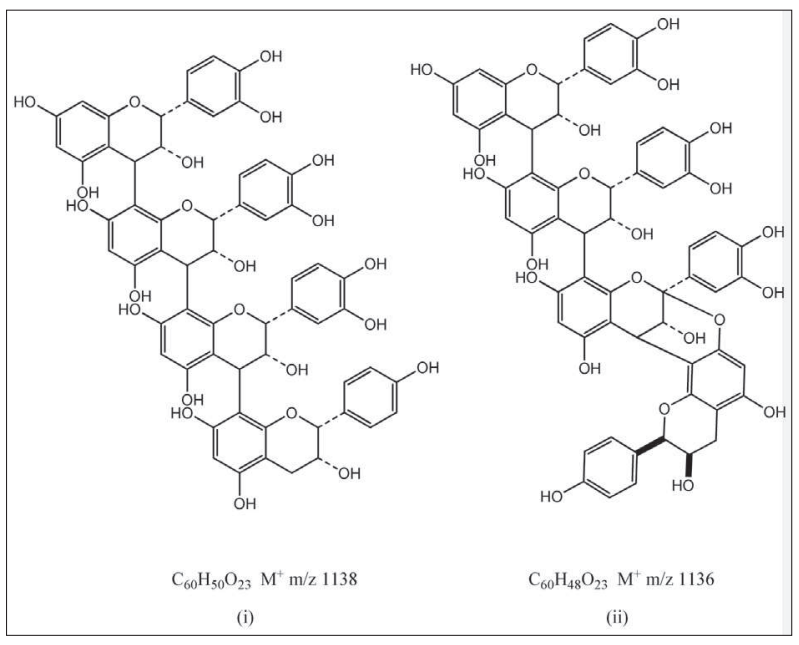

Figure 3: Proanthocyanidin structures: (i) B-type proanthocyanidin tetramer and (ii) A- type proanthocyanidin tetramer

tetramers present in $\mathrm{PA}_{1}$, as well as sharp intense signals with a narrow signal width were observed at $\mathrm{m} / \mathrm{z} 633.3$ and 617.3. It is likely that the fragments at $\mathrm{m} / \mathrm{z} 633.3$ and $617.3 \mathrm{had}$ arisen from epigallocatechin 3,5-di- $O$-gallate $[610+\mathrm{Na}]^{+}$and epicatechin 3,5-di-O-gallate $[594+\mathrm{Na}]^{+}$ respectively, which had been isolated and characterised previously from green tea leaves (Nonaka et al., 1983; Kiehne et al., 1997; Kumar et al., 2009). Therefore PA was a mixture of PA tetramers and the two galloylated catechins above.

The ESI-MS of $\mathrm{PA}_{3}$ in the negative ionization mode exhibited a cluster of ions at $\mathrm{m} / \mathrm{z}$ 901.7, 882.1, 881.1 and 878.9. In the absence of an MS/MS system, the authors assigned the peaks at $\mathrm{m} / \mathrm{z} 881.1$ and 882.1 to a PA dimer (epi)catechingallate-(epi)catechin gallate, and/ or (epi)afzelechin-(epi)gallocatechin gallate based on their previous isolation from a tea extract using HSCCC (Kumar et al., 2009).

\section{Antibacterial activity of proanthocyanidin fractions}

The results of the current investigation on susceptibility tests clearly indicated the varying levels of activity of fractions $\mathrm{F}_{1}-\mathrm{F}_{4}$ against standard strains of $S$. aureus (ATCC 25923 and NCTC 6571): $F_{1}$ was inactive against both the strains at a concentration of $\leq 10 \mu \mathrm{g} / \mathrm{mL}$; $\mathrm{F}_{2}$ was inactive against ATCCC 25923 at $\leq 10 \mathrm{mg} \mu \mathrm{g} / \mathrm{mL}$ but inhibited NCTC 6571 at $6 \mu \mathrm{g} / \mathrm{mL} ; \mathrm{F}_{3}$ inhibited ATCC 25923 and NCTC 6571 at $3 \mu \mathrm{g} / \mathrm{mL}$ and $1 \mu \mathrm{g} / \mathrm{mL}$, respectively. $\mathrm{F}_{4}$ was the most active of the four fractions $\mathrm{F}_{1}-\mathrm{F}_{4}$ and displayed moderate anti-staphylococcal activity against the standard strains of $S$. aureus, and the strains obtained from clinical isolates (Table 1). It is noteworthy that fraction $\mathrm{F}_{1}$ contained only monomeric flavan-3-ols 
Table 1: Diameters ${ }^{\mathrm{a}}(\mathrm{mm})$ of the inhibition zones for varying concentrations of fraction $\mathrm{F}_{4}$ against $S$. aureus standard strains and clinical isolates in the agar well diffusion assay

\begin{tabular}{ccccccc}
\hline $\mathrm{F}_{4}$ & \multicolumn{5}{c}{ Strain of S. aureus } \\
$\begin{array}{c}\text { Fraction } \\
(\mathrm{mg} / \mathrm{mL})\end{array}$ & ATCC & NCTC & MRSA & MRSA & MSSA & MSSA \\
\hline 1 & 13 & 15 & 17 & 14 & 16 & 14 \\
0.9 & 13 & 15 & 16 & 13 & 15 & 14 \\
0.8 & 11 & 15 & 16 & 13 & 14 & 13 \\
0.7 & 11 & 15 & 15 & 12 & 13 & 13 \\
0.6 & 11 & 14 & 12 & 11 & 12 & 13 \\
0.5 & 11 & 14 & 11 & 11 & 12 & 13 \\
0.4 & 11 & 13 & NI & NI & 11 & 12 \\
0.3 & NI & 13 & NI & NI & 11 & 12 \\
0.2 & NI & 13 & ND & ND & ND & ND \\
Water & NI & NI & NI & NI & NI & NI \\
Positive & 15 & 15 & 15 & 15 & 15 & 15 \\
control $^{\mathrm{d}}$ & & & & & & \\
\hline
\end{tabular}

a Diameter of the agar well was $9 \mathrm{~mm}$ except for positive control $(5 \mathrm{~mm})$

${ }^{\mathrm{b}} \mathrm{NI}=$ No inhibition; ${ }^{\mathrm{c}} \mathrm{ND}=$ Not determined

${ }^{\mathrm{d}}$ Methicillin $(10 \mu \mathrm{g})$ for MSSA and gentamicin $(5 \mu \mathrm{g})$ for MRSA

while fraction $\mathrm{F}_{4}$ contained oligomeric PAs. This is in agreement with the observation made by Mayer et al. (2008), that fractions containing only monomers such as (epi)catechin did not show antibacterial activity except against Pseudomonas aeruginosa (ATCCC 27853).

MICs of the three PA fractions obtained after HSCCC of $\mathrm{F}_{4}$ were determined against a wider range of MRSA and MSSA strains. The values ranged between $512-1024 \mu \mathrm{g} / \mathrm{mL}$ (Table 2) and indicated moderate activity. Of the three fractions, $\mathrm{PA}_{3}$ appeared to be the most active against $S$. aureus. ESI-MS evidence suggested the dimeric nature of the PAs in this fraction. In this context it is relevant that the biological activity of PAs from grape seed extract is associated with the presence of gallate esters of dimeric and trimeric PAs (Agarwal et al., 2007).

The oligomeric PAs that were isolated from fresh tea leaves exhibited moderate activity against MRSA, MSSA, and the standard strains of S. aureus, NCTC 6571 and ATCC 25923. The MICs of the PAs that were tested during this study varied between $512-1024 \mu \mathrm{g} / \mathrm{mL}$. However, these results may not accurately reflect the true potency of the PAs because a low rate of diffusion of the potent PAs in the agar medium may have resulted in higher MIC values, due to the fact that the rate of diffusion of PAs in the agar medium may also be influenced by the
Table 2: Minimum inhibitory concentration (MIC) $(\mu \mathrm{g} / \mathrm{mL})$ of proanthocyanidin fractions $\mathrm{PA}_{1}-\mathrm{PA}_{3}$ against $S$. aureus reference strains and clinical isolates of MRSA and MSSA

\begin{tabular}{|c|c|c|c|}
\hline S. aureus strain & $\mathrm{PA}_{1}$ & $\mathrm{PA}_{2}$ & $\mathrm{PA}_{3}$ \\
\hline NCTC 6571 & 512 & 512 & 512 \\
\hline ATCC 25923 & 512 & 512 & 512 \\
\hline MRSA 0038 & 1024 & 1024 & 512 \\
\hline MRSA 0044 & 512 & 512 & 1024 \\
\hline MRSA 0053 & 1024 & 1024 & 512 \\
\hline MRSA 0056 & 512 & 512 & 512 \\
\hline MRSA 0058 & 512 & 512 & 512 \\
\hline MRSA 0074 & 512 & 512 & 512 \\
\hline MRSA 0151 & 512 & 512 & 512 \\
\hline MRSA 0167 & 1024 & 512 & 512 \\
\hline MRSA 2735 & 512 & 1024 & 512 \\
\hline MRSA 2880 & 512 & 1024 & 1024 \\
\hline MRSA 2919 & 512 & 1024 & 1024 \\
\hline MRSA 3019 & 1024 & 1024 & 512 \\
\hline MSSA 0091 & 1024 & 1024 & 1024 \\
\hline MSSA 0098 & 1024 & 1024 & 512 \\
\hline MSSA 0175 & 1024 & 1024 & 512 \\
\hline MSSA 2815 & 1024 & 512 & 512 \\
\hline MSSA 2848 & 1024 & 1024 & 1024 \\
\hline MSSA 2851 & 1024 & 512 & 512 \\
\hline MSSA 2886 & 1024 & 1024 & 1024 \\
\hline MSSA 2901 & 512 & 1024 & 512 \\
\hline MSSA 2902 & 512 & 512 & 512 \\
\hline MSSA 2920 & 1024 & 1024 & 512 \\
\hline MSSA 2935 & 1024 & 1024 & 512 \\
\hline
\end{tabular}

number of hydroxyl groups present in the polyphenolic molecules (Zheng et al., 1996).

\section{CONCLUSION}

Oligomeric proanthocyanidins, including those having tetramers with A-type linkages are found in fresh tea leaves and display moderate antibacterial activity against both MRSA and MSSA.

\section{Acknowledgement}

The authors thank the Department of Chemistry, University of Ruhuna, Sri Lanka, for probationary study leave granted to Sujeewa K. Hettihewa; Dr. Sarath Gunasekera of the Harbour Branch Oceanographic Institue at Florida Atlantic University, USA, for providing ESI-MS data; the National Research Council of Sri Lanka and the National Science Foundation of Sri 
Lanka for research funding; and Mr. S. Wickramasinghe, Department of Chemistry, University of Peradeniya, for technical assistance.

\section{REFERENCES}

1. Agarwal C., Veluri R., Kuar M., Chou S.C., Thompson J.A. \& Agarwal R. (2007). Fractionation of high molecular weight tannins in grape seed extract and identification of procyanidin B2-3,3'-di-O-gallate as a major active constituent causing growth inhibition and apoptotic death of DU145 human prostate carcinoma cells. Carcinogenesis 28: $1478-1488$.

DOI: http://dx.doi.org/10.1093/carcin/bgm045

2. Andrews J.M.(2001). Determination of minimum inhibitory concentrations. Journal of Antimicrobial Chemotherapy 48: $5-16$.

DOI: http://dx.doi.org/10.1093/jac/48.suppl_1.5

3. Balde A.M., De Bruyne T., Pieters L., Koldziel H., Berghe D.V., Claeys M. \& Vlietnick A. (1990). Plant antiviral agents. VII. Antiviral and antibacterial proanthocyanidins from the bark of Pavetta owariensis. Phytotherapy Research 4(5): $182-188$.

DOI: http://dx.doi.org/10.1002/ptr.2650040505

4. Degenhardt A., Engelhardt U.H., Lakenbrink C. \& Winterhalter P. (2000). Preparative separation of polyphenols from tea by high-speed countercurrent chromatography. Journal of Agricultural and Food Chemistry 48: 3425 - 3430.

DOI: http://dx.doi.org/10.1021/jf0000833

5. Foo L.Y., Lu Y., Howell A.B. \& Vorsa N. (2000). A-type proanthocyanidin trimers from Cranberry that inhibit adherence of uropathogenic P-fimbriated Escherichia coli. Journal of Natural Products 63: 1225 - 1228.

DOI: http://dx.doi.org/10.1021/np000128u

6. Hashimoto F., Nonaka G. \& Nishoka I. (1989). Tannins and related compounds. XC. 8-C-ascorbyl(-)epigallocatechin 3-O-gallate and novel dimeric flavan3-ols, oolonghombisflavans A and B, from oolong tea. Chemical and Pharmaceutical Bulletin 37: 3255 - 3263. DOI: http://dx.doi.org/10.1248/cpb.37.3255

7. Howell A.B., Reed J.D., Krueger C.G., Winterbottom R., Cunningham D.G. \& Leahy M. (2005). A-type cranberry proanthocyanidins and uropathogenic bacterial antiadhesion activity. Phytochemistry 66: $2281-2291$. DOI: http://dx.doi.org/10.1016/j.phytochem.2005.05.022

8. Ito Y. \& Conway W.D. (1996). High-speed Counter-Current Chromatography, p. 34. Wiley, New York, USA.

9. Kiehne A., Lakenbrink C. \& Engelhardt U.H. (1997). Analysis of proanthocyanidins in tea samples. Zeitschrift für Lebensmittel-Untersuchung und -Forschung 205: $153-157$.

DOI: http://dx.doi.org/10.1007/s002170050144

10. Kumar N.S. \& Rajapaksha M. (2005). Separation of catechin constituents from five tea cultivars using high speed countercurrent chromatography. Journal of Chromatography A 1083: 223 - 228.

DOI: http://dx.doi.org/10.1016/j.chroma.2005.06.013
11. Kumar N.S., Wijekoon W.M.A.M.B., Kumar V., Punyasiri P.A.N. \& Abeysinghe I.S.B. (2009). Separation of proanthocyanidins isolated from tea leaves using highspeed counter-current chromatography. Journal of Chromatography A 1216: 4295 - 4302.

DOI: http://dx.doi.org/10.1016/j.chroma.2008.12.025

12. Kumar N.S., Bandara B.M.R. \& Hettihewa S.K. (2013). Journal of Liquid Chromatography and Related Technologies. Under review.

13. Lakenbrink C., Engelhardt U.H. \& Wray V. (1999). Identification of two novel proanthocyanidins in green tea. Journal of Agricultural and Food Chemistry 47: $4621-4624$. DOI: http://dx.doi.org/10.1021/jf9813081

14. Li Y.G., Tanner G. \& Larkin P.J. (1996). The DMACA-HCl protocol and the threshold proanthocyanidin content for bloat safety in forage legumes. Journal of the Science of Food and Agriculture 70: 89 - 101.

15. Mayer R. et al. (11 authors) (2008). Proanthocyanidins: target comounds as antibacterial agents. Journal of Agricultural and Food Chemistry 56: 6959 - 6966. DOI: http://dx.doi.org/10.1021/jf800832r

16. Nonaka G.I., Morimoto S. \& Nishioka I. (1983). Tannins and related compounds. part 13. Isolation and structures of trimeric, tetrameric and pentameric proanthocyanidins from cinnamon. Journal of the Chemical Society. Perkin Transactions I : $2139-2145$.

17. Nonaka G.I., Sakai R. \& Nishioka I. (1984). Hydrolysable tannins and proanthocyandins in green tea. Phytochemistry 23: $1753-1755$.

18. Robertson A. (1992). The chemistry and biochemistry of black tea production - the non-volatiles. Tea Cultivation to Consumption (eds. K.C. Wilson \& M.N. Clifford), pp 555 - 601. Chapman and Hall, London, UK.

19. Rohr G.E., Riggio G., Meier B. \& Sticher O. (2000). Evaluation of different detection modes for the analysis of procyanidins in leaves and flower of Crataegus spp. Part II. Liquid chromatography-mass spectrometry. Phytochemical Analysis 11: 113 - 120.

20. Santos-Buelga C. \& Scalbert A. (2000) Proanthocyanidins and tannin like compounds - nature, occurrence, dietary intake and effects on nutrition and health. Journal of the Science of Food and Agriculture 80: 1094 - 1117.

21. Valgas C., de Souza S.M., Smamia E.F.A. \& Smamia J.A. (2007). Screening methods to determine antibacterial activity of natural products. Brazilian Journal of Microbiology 38: 369 - 380 .

DOI: http://dx.doi.org/10.1590/S1517-83822007000200034

22. Yanagida A., Shoji Y., Shishubusawa H., Shindu M., Tagashira M., Okeda Y. \& Ito Y. (2006). Analytical separation of tea catechins and food related polyphenols by high-speed counter-current chromatography. Journal of Chromatography A 1112: 197 - 201.

DOI: http://dx.doi.org/10.1016/j.chroma.2005.09.086

23. Zheng W.F., Tan R.X., Yang L. \& Liu Z.L. (1996). Two flavones from Artemisia giraldi and their antimicrobial activity. Planta Medica 62: 160 - 162. DOI: http://dx.doi.org/10.1055/s-2006-957841 